\title{
Community-Based Tourism as an Effective Approach towards Realizing Sustainable Development
}

\author{
Baiartis Lyngdoh Peinlang \\ Ph. D. Scholar, Department of Adult and Continuing Education, North-Eastern Hill University, \\ Mawlai Umshing, Shillong, Meghalaya, India-793022
}

\begin{abstract}
The purpose of this paper is to highlight the viability of Community-Based Tourism (CBT) for achieving sustainable development. The paper pointed out an argument on the facts that CBT befits itself as an active player in the sustainable development arena. Moreover, the paper pointed out the need for conscientization (Freire, 1973) to initiate a strong reaction among the community people including the deprived section of society to be aware of their own socioeconomic situation, and their relationship with the natural environment so that they would collectively initiate action and take control over community developmental process for a positive change in the community.
\end{abstract}

Keywords - Community-Based Tourism; Sustainable Development; Social; Environmental; Complementarity; Conscientization

\section{Introduction}

CBT is defined as a process of collective responsibility of communities to participate actively in pro-poor tourism development initiatives and the benefit on account of participation is contrived through the investment made by visitors for the products or services consumed, or simply for their entry into the concerned attraction sites. CBT principles allow all residents in a particular community to actively participate in tourism development according to their skills and capability irrespective of caste or greed, rich or poor, young or old. CBT also allows for delegated power and citizen control over management and benefit sharing and the host community get a chance to be involved actively in decision-making process. In this case the host residents feel a sense of pride as they can create a platform to showcase their culture and traditional practices, get to learn how to interact among themselves and with the tourists and hence help developing a positive attitude towards participation in any developmental activity. By being able to showcase their culture to the world, the local residents would also feel the need to preserve and revive their old age practices and customary practices as they do understand the economic value of showcasing their culture to the world. Furthermore, CBT depends largely on the beauty and greenery of landscapes, waterfalls, caves, lakes and pools, etc. hence people would feel the need for retention of greenery, cleanliness and beauty of the natural world. In this sense CBT positions itself as more appropriate approach for upholding the social, economic and environmental goal of sustainable development.

\section{Significance of CBT}

The UN conference on Environment and Development, 1992 held in Rio de Janeiro has identified tourism as one among the five industries capable of rolling the wheel towards sustainable development for being an industry without smoke. WCED (1987) recognized three important parameters of sustainable development viz. economic, social and environmental.

- Economic- The economic aspect of sustainable development asserted a conscious interaction between man and environment in the process of obtaining benefits from ecosystem services for a better quality of life. All anthropogenic processes should not go beyond the capacity of the natural environment to replenish itself. In fact man should involve himself in a trade off with the natural environment. Involvement in trade off with the natural environment implies that while man depends on nature for survival, he should pay back through innovative actions to enhance the environment.

- Social- The social aspect of sustainable development stresses on promoting a mutual understanding and cohesion between communities and a fair distribution of resources to all mankind irrespective of races, generations, ethnicity or territory. It involves designing one's own life plans by articulating needs and interests without limiting the rights and general opportunities of other people and future generations and also to present ways of empathy and solidarity with the poor, needy and oppressed people and communities (Grapentin and Dannenberg, 2016).

- Environmental- Environmental aspect of sustainable development asserted the essence of sustaining all forms of life on earth in order to maintain a balance in the interaction between man and the bio-physical systems. An imbalance may result in crisis in the form of natural calamities and epidemics. Hence the structure and function of ecological systems on earth should not be distorted beyond certain limits.

The essence of sustainable development concept has been understood since the early 1970s. Since the UN

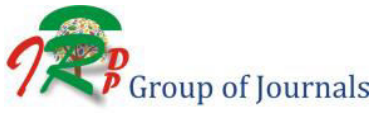


conference on Environment and Development, 1992, frameworks and strategies had been adopted to prevent climate change, desertification and to conserve biodiversity. Many countries of the world have come to the realization of the immediate need to formulate environmental policies in order to reduce the chance of environmental crisis. However, at times the actual implementation of environmental polices led to termination of people's means of earning their livelihood and hence social and economic sustainable development objectives are not fully realized. It is necessary that alternative approaches to earning livelihood must be evolved if the old practices have to be curbed for the sake of preventing ecological crisis.

On the basis of the above argument, the present study proposes CBT as one of the plausible alternative approaches in order to achieve the objective of sustainable development in its full sense. CBT not help to understand the value of environmental conservation but it also create job opportunities to help raising the income of the people, help raising the quality of life, promote community pride, foster cultural exchange, embed development in local culture, enables participation of local people in the process of development and ensure rights in natural resource management (CREST, 2012). In CBT development, the natural environment is the direct provider of raw material for use as tourism products. For instance, the serene landscapes, caves, pristine waterfalls, natural lakes and pools, flora and fauna of a place are elements of attraction for tourists and hence these are used directly as products for sightseeing, caving, trekking water sports, etc. Hence it is quite pertinent that host communities would understand the economic value of these attractions and their preservation would bring economic benefit in the long run. Therefore, the utility of CBT in ecosystem preservation is more feasible compared to other approaches for bringing long term economic development. Moreover, CBT principles bring forth a sense of complementarity among all human and non-human forms in such a way that each human being would complement other human beings and non-human forms with his/her own capacities to produce a richer, creative, and developmental whole-not as a "dominant" species but as a supportive one (Bookchin, 1921).

\section{An approach to sustainable CBT}

Gibson (1996) stated that the challenges faced by communities came up as a result of depletion of economic, social and environmental resources which are interconnected. He further stated that social problems like child abuse, diseases, accidents, destruction of natural resources, lack of good jobs, poverty, etc. cannot be solved unless the way of taking action is changed from being symptomatic to being systemic. Sustainable development recognizes the concept of creating a future in which human society and nature can co-exist with mutual benefit and in which the suffering caused by poverty and natural resource abuse is eliminated (Gibson in Flint, 2013).

The challenges on account of climate change, poverty and resource depletion have further underlined the importance of balancing economic development and natural resource conservation. If poor rural people are to overcome poverty, they must have the opportunity to build the assets, knowledge, skills and confidence they need to pursue their own economic agenda better. Moreover, to address rural poverty, one must realize the potential linkages between poverty and natural resources and that the rural poor should have improved and more equitable access to those resources. It is only when one feels that the natural resources available around him are his own that one begins to develop a sense of stewardship or caring towards those resources and eventually to develop an efficient sustainable management system of the resource base. Individually, poor rural people might remain marginalized but by building their own collective organizations they can better manage assets, negotiate with market intermediaries, and access economic opportunities, service providers and government officials(IFAD, 2006; Lee and Neves, 2009).Here we realize the essence of community collective action or community participation in sustainable development. Any approach of improving rural livelihood requires community participation which is widely recognized as a basic operational principle of rural development. In the context of Adult and Continuing Education in India, the first and foremost approach is conscientization (Freire, 1973)i.e., to make the people aware of their own situation in the society and environment through reflection and action, through local participation and mutual understanding and shared experience and through a strong dialogic action challenges mediating social realities by posing them as problems that can be analysed seriously by those who have direct experience of them. Perhaps conscientization consequently provokes the community to take action with a sense of community participation to fight against poverty and ignorance by positioning themselves at the topmost rung in the ladder of community participation, i.e. by gaining delegated power and citizen control (Zhang, 2010) over the process of development.

\section{Conclusion}

In view of the above arguments and facts, it can be concluded that CBT is such a befitting alternative approach to help poor communities to achieve sustainable development as it is pro-poor and requires collective or community active participation in order to achieve the goal of a long term economic gain and strong social cohesion. It 
is a learning process to change the outlook of the society and help to develop a positive attitude among local residents towards community development. Lastly, since CBT requires retention of greenery, beauty, cleanliness, serenity of landscapes and all forms of ecosystems in order to attract tourists, it proves itself as a befitting approach to achieve environmental management goals in the long run.

\section{References}

[1] Bookchin, M. (1921). The Ecology of Freedom-The Emergence and Dissolution of Hierarchy, California, Ceshire Books Inc.

[2] Freire, P. (1973). Pedagogy of the Oppressed. New York: Seabury Press.

[3] Lee, D.R. and Neves, B. (2009). Rural Poverty and Natural Resources: Improving Access and Sustainable Management. Agricultural Development Economics Division, FAO.
[4] Flint, D.J. and Golicic, S.L. (2009). Searching for competitive advantage through sustainability: a qualitative study in the New Zealand wine industry. International Journal of Physical Distribution \& Logistics Management 39(10), 841-860.

[5] Zhang, Y. (2010). Personal factors that influence residents' preferences about community involvement in tourism planning, Indiana University.

[6] Sascha Dannenberg and Theresa Grapentin (2016), "Education for Sustainable Development-Learning for Transformation. The Example of Germany", Journal of Future Studies, Volume 20, No.3, pp 7-20.

[7] https://www.responsibletravel.org/whoWeAre/CREST\%20Mileston es\%202015\%20Update_Final.pdf.

[8] Report of the World Commission on Environment and Development (1987): United Nations.

[9] A New Approach to Sustainable Tourism Development-Moving beyond Environmental Protection (2003): United Nations. 